\title{
Noncoding Genes on Sex Chromosomes and Their Function in Sex Determination, Dosage Compensation, Male Traits, and Diseases
}

\author{
Michelle C. Maier ${ }^{a, b}$ Molly-Rose A. Mclnerney ${ }^{a, b} \quad$ Jennifer A. Marshall Graves ${ }^{c}$ \\ Fadi J. Charchara, d, e

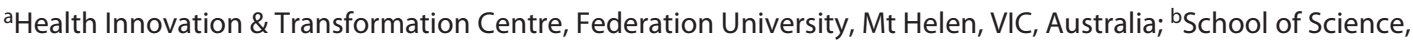 \\ Psychology and Sport, Federation University Australia, Ballarat, VIC, Australia; 'School of Life Sciences, La Trobe \\ University, Melbourne, VIC, Australia; 'Department of Cardiovascular Sciences, University of Leicester, Leicester, \\ United Kingdom; 'Department of Anatomy and Physiology, University of Melbourne, Melbourne, VIC, Australia
}

\section{Keywords}

Cardiovascular disease - circRNA - Evolution - Gene

regulation · lincRNA - IncRNA - Mammalian sex

determination - miRNA - mRNA - Noncoding RNA · Sex

chromosomes - Species evolution - SRY W W chromosome .

$X$ chromosome $\cdot$ Xist $\cdot Y$ chromosome $\cdot Z$ chromosome

\section{Abstract}

The mammalian $Y$ chromosome has evolved in many species into a specialized chromosome that contributes to sex development among other male phenotypes. This function is well studied in terms of protein-coding genes. Less is known about the noncoding genome on the $\mathrm{Y}$ chromosome and its contribution to both sex development and other traits. Once considered junk genetic material, noncoding RNAs are now known to contribute to the regulation of gene expression and to play an important role in refining cellular functions. The prime examples are noncoding genes on the $\mathrm{X}$ chromosome, which mitigate the differential dosage of genes on sex chromosomes. Here, we discuss the evolution of noncoding RNAs on the $Y$ chromosome and the emerging evidence of how micro, long, and circular noncoding RNAs transcribed

karger@karger.com

(c) 2021 S. Karger AG, Basel

www.karger.com/sxd

Karger" from the $Y$ chromosome contribute to sex differentiation. We briefly touch on emerging evidence that these noncoding RNAs also contribute to some other important clinical phenotypes in humans.

(c) 2021 S. Karger AG, Basel

\section{Mammalian Sex Chromosome Evolution}

The organization and function of mammalian sex chromosomes owes as much to their peculiar evolutionary trajectory as to their fitness for purpose.

Sex chromosomes have arisen independently many times during vertebrate evolution when a new sex determining gene is acquired by a chromosome pair. Linkage with sex instantly changes the dynamics of this chromosome such that other gene variants which confer an advantage to one or the other sex accumulate near the sexdetermining locus, and recombination between the sexspecific chromosome and its erstwhile homologue is suppressed to keep the package of sex-specific variants together [Ellegren, 2011; Saunders et al., 2019]. Loss of recombination leads to accumulation of mutations and 
deletions in the sex-specific chromosome, leading to its rapid degradation and eventual disappearance [Graves, 2006; Bachtrog, 2013]. Such cycles of acquisition, differentiation, and loss have been observed in many vertebrate and invertebrate lineages [Ortega et al., 2019].

Generation of novel sex determining genes has resulted in the huge variety among vertebrates such that it may appear that almost any gene can take on this function [Graves, 2013; Bachtrog et al., 2014]. However, there are patterns and limitations. Formally, sex determining genes may either promote or inhibit development of either male or female [Arnold, 2017]. Acquisition of a male-dominant gene defines a $\mathrm{Y}$ chromosome that is male-specific, such as the sex-determining region $\mathrm{Y}(S R Y)$ gene in mammals, and sets up an XX female:XY male system [Charlesworth, 1996]. Acquisition of a male-inhibitor allele, on the other hand, defines a W chromosome that is female specific, such as Dmw in Xenopus laevis, and sets up a ZZ male:ZW female system [Yoshimoto et al., 2010; Yoshimoto and Ito, 2011]. In birds as well as many reptiles and fish, it is the dosage of a sex-determining gene that sends development down a male- or female-determining pathway [Alam et al., 2018]. For instance, the Double-sex and Mab-3 Related Transcription Factor 1 (Dmrt1) in birds is present on the $\mathrm{Z}$ but not the $\mathrm{W}$ chromosome [Jeng et al., 2019]. Two copies are required to be male, so males are $\mathrm{ZZ}$ and females ZW [Yoshimoto and Ito, 2011]. Dosage of a female-determining gene is also theoretically possible and sets up an XX female:XY male system as in Drosophila [Cline, 1984].

The origin of sex determining genes is usually one or other of the $60+$ genes in the complex vertebrate sex-determining pathway [Bachtrog, 2013]. For instance, Dmrt1, which is sex determining in several reptiles and fish as well as birds, has a conserved role stabilizing testis development in mammals, and copies of this gene may be repurposed as a male-dominant gene (e.g., Dmy in medaka fish) or an inhibitor (e.g., Dmw in X. laevis) [Trukhina et al., 2013].

Dmrt1 is reported to be the key factor in sex determination in birds. Ioannidis et al. [2021] utilised a CRISPR/ Cas9-based monoallelic targeting approach resulting in a single functional copy of Dmrt1. This led to chickens developing ovaries in place of testes, therefore demonstrating that the sex-determining system in avian species is dependent on Dmrt1 dosage. Dmrt1 is reported to be the key factor in sex determination in birds.

The mammalian $S R Y$ evolved from an ancient transcription factor, SRY-line HMG Box Transcription Factor 3 (SOX3) simply by a rearrangement that sent its ex- pression into the developing gonad: homologues of this gene are sex determining in a frog and fish species [Graves, 1998]. Anti-müllerian hormone $(\mathrm{Amh})$, which is essential for the male-specific inhibition of female reproductive ducts in mammals, is sex determining in some fish and perhaps the platypus [Veyrunes et al., 2008; Cortez et al., 2014]. The acquisition of a sex determining function by this variety of genes means that sex chromosomes in different lineages have quite different origins and bear different sets of genes [Graves, 1998].

Turnover of the sex-determining gene can be extremely frequent in reptiles, amphibians, and fish and may helped along by the influence of environmental cues like temperature on sexual development [Janzen and Paukstis, 1991; Holleley et al., 2015]. Turnover is rare in mammals and birds, perhaps because homeothermy makes temperature sex determination impossible. However, the cycle of Y chromosome attrition promotes turnover, even in mammals [Janzen and Paukstis, 1991].

The mammalian (including human) XY chromosome pair illustrates this cycle of birth, differentiation, degradation, and loss of a male-specific $\mathrm{Y}$ chromosome. The human $\mathrm{Y}$ chromosome is much smaller than the $\mathrm{X}$, contains few protein-coding genes, and is largely composed of highly repetitive sequence (Fig. 1) [Quintana-Murci and Fellous, 2001]. Only the very tip of the Y retains homology with the X over a pseudoautosomal region (PAR) that contains about 25 genes. The PAR pairs at meiosis and is critical for sex chromosome segregation and spermatogenesis [Quintana-Murci and Fellous, 2001].

The mammalian $\mathrm{X}$ chromosome contains more than 1,000 protein-coding genes and is almost completely conserved among mammals, perhaps protected by the chromosome-wide $\mathrm{X}$ chromosome inactivation mechanism that ensures dosage compensation between the sexes [Prothero et al., 2009]. It has homology to a chromosome or chromosome regions in all vertebrates and shares $S O X 3$, the gene from which SRY evolved [Graves and Peichel, 2010].

In contrast, the male-specific portion of the human $\mathrm{Y}$ (MSY) chromosome bears only 27 protein-coding genes, most of which have homology to conserved genes on the $\mathrm{X}$, from which they obviously diverged [Skaletsky et al., 2003]. However, a few genes arose from the insertion of gene copies transposed or retrotransposed from autosomes (e.g., DAZ1) or the X (e.g., PCDH11Y) [Ghenu et al., 2016]. Several Y genes, including those that evolved from $\mathrm{X}$ genes (such as RBMY) have been greatly amplified and are present in tandem arrays on enormous loops, whose arms bear complementary (palindromic) sequenc- 


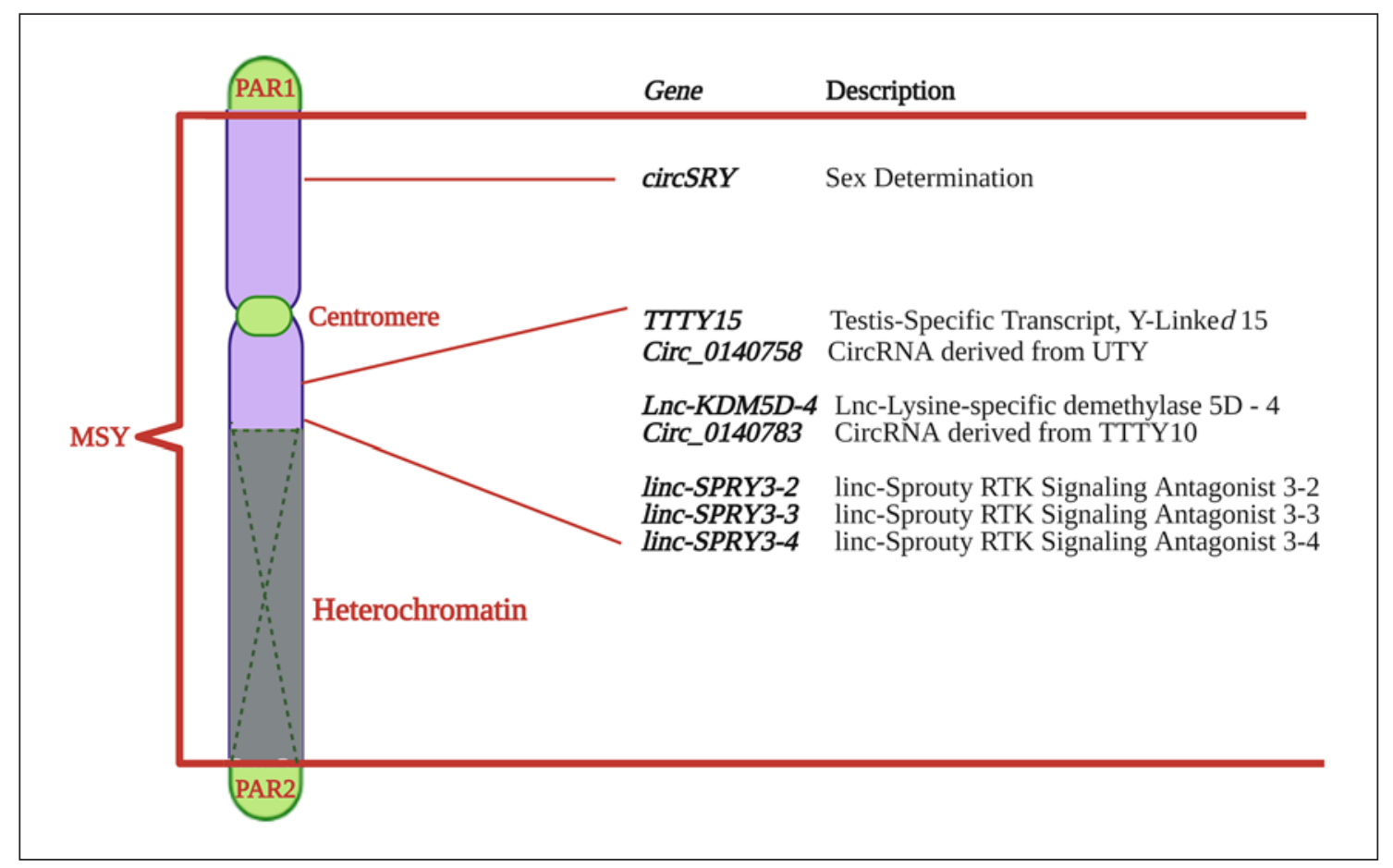

Fig. 1. Structure of the human Y chromosome. Each terminal end of the Y chromosome harbours the pseudoautosomal regions (PAR1 and PAR2). The heterochromatin (grey section) is genetically inactive and the region within each of the PAR regions is the male specific region on Y (MSY). The block of black text illustrates Y-linked noncoding genes that play a role in male disease, while circSRY contributes to male sex determination.

es [Ghenu et al., 2016]. These sequences can undergo gene conversion, which could correct mutations that arise in the multiple arrays or may hasten their pseudogenization (presumable the reason for the high proportion of inactive copies). The reasons why these few genes have survived the inexorable degradation of the $\mathrm{Y}$ have been debated for decades. Some have obviously taken on male-specific functions (for instance $R B M Y$, essential for spermatogenesis, evolved from $R B M X$, essential for brain development) [Tsend-Ayush et al., 2005] whereas others seem to be dose sensitive so their loss from the $\mathrm{Y}$ would present severe dosage imbalance (e.g., KDM5C and ZFY) [Bellott et al., 2014]. The degradation of the Y chromosome has proceeded to different extents in different lineages [Bachtrog, 2013]. The primate (especially human) $\mathrm{Y}$ seems to have been reasonably stable over the last few million years [Hughes et al., 2012], whereas the mouse Y retains few essential genes [Morgan and Pardo-Manuel De Villena, 2017] and some rodent species have lost the Y (and Sry) entirely [Mulugeta et al., 2016; Ortega et al., 2019]. While most attention has been given to proteincoding genes on the human $\mathrm{Y}$ chromosome, the transcription from at least a few noncoding RNAs (ncRNAs) on the $\mathrm{Y}$ chromosome have been recognised relatively recently [Molina et al., 2017; Lai et al., 2019; Xiao et al., 2019].

\section{Noncoding RNA Derivation and Function}

ncRNAs do not encode proteins, but they may exhibit regulatory function [Farazi et al., 2008]. Regulatory ncRNAs can be divided into small RNAs with fewer than 200 nucleotides and long ncRNAs (lncRNAs) with a length greater than 200 nucleotides [Kim et al., 2009].

Small ncRNAs can be further subdivided into endogenous small interfering RNAs (endo-siRNAs), PIWI-associated RNAs (piRNAs), and microRNAs (miRNAs) [Farazi et al., 2008; Kim et al., 2009]. Endo-siRNA are derived from complementary double-stranded RNAs formed through sense-antisense transcript pairs and transposon transcripts [Golden et al., 2008]. These endosiRNAs have been found to contribute to the repression of transposons [Song et al., 2011]. Small RNAs, piRNAs, on the other hand, are formed from single-stranded piRNA precursor transcripts [Vagin et al., 2006] and have 
been reported in transposon silencing via heterochromatin formation and RNA destabilization [Klattenhoff and Theurkauf, 2008]. One of the most investigated ncRNA classes has been miRNAs. miRNAs are transcribed by RNA polymerase II and further processed in the cytoplasm by the enzyme Dicer, producing a 21-23-nt long miRNA duplex. One strand of this duplex can mediate sequence-specific binding to target messenger RNAs (mRNAs), which are subsequently silenced or degraded [Farazi et al., 2008; Kim et al., 2009].

Many long ncRNAs have also been identified [Okazaki et al., 2002; Carninci et al., 2005], varying in length from $200 \mathrm{bp}$ to several kilobases. LncRNAs are transcribed by RNA polymerase II from different regions of the genome. Several derive from intergenic regions [Guttman et al., 2011; Ulitsky and David, 2013], while others derive from the sense or antisense strand of protein-coding genes [Wu et al., 2014]. Many lncRNAs are considered to be general by-products of transcription, RNA processing, and splicing, but they may also exhibit specificity of expression and function [Fatica and Bozzoni, 2014]. lncRNA functions involve regulating chromatin remodelling, controlling transcription rate of genes, and influencing post-transcriptional processes through inhibition or induction of translation [Mercer et al., 2009; Fatica and Bozzoni, 2014].

Circular RNAs (circRNAs) are emerging as an important class of regulatory ncRNAs. CircRNAs are a covalent closed loop and lack the polyadenylated tail seen in messenger RNA [Qu et al., 2015]. They originate from protein-coding genes [Pamudurti et al., 2017] and have been suggested to act as sponges that regulate miRNAs [Legnini et al., 2017; Pamudurti et al., 2017]. CircRNA expression also seems to be highly abundant in comparison with their linear isomers [Jeck et al., 2013]. Due to their closed structure, circRNAs are very stable and have exonuclease resistance properties [Holdt et al., 2018]. CircRNAs have been found to be highly tissue specific and expressed in peripheral blood of humans [Memczak et al., 2015] with potential use as biomarkers.

\section{Role of Noncoding RNA from Sex Chromosomes in Sex Determination}

Various ncRNAs are involved in the sex determination and dosage compensation in invertebrates. In Drosophila melanogaster, specification of sex is controlled by alternative splicing of the gene Sex-lethal $(S x l)$ which is triggered by the dosage of X chromosome "numerator genes".
Noncoding transcripts from 2 regions upstream of the $S x l$ promotor affect the chromatin state around the promotor. The antisense transcript from one, in partnership with proteins of the 5 "numerator genes", changes the chromatin conformation around the $S x l$ promoter and permits transcription of the full-length gene that is required for female development [Mulvey et al., 2014]. Expression of lncRNAs in transgenic lines demonstrate that they impact not only sex determination but alter levels of other lncRNA [Mulvey et al., 2014].

In invertebrate sex determination, a cell-autonomous process is usually occurring throughout the embryo [Girard et al., 2006; Lau et al., 2006; Watanabe et al., 2006]. Other invertebrate sex-determining systems involve small ncRNAs. Bombyx mori (silkworm) has an ZW female:ZZ male system. The female-specific $\mathrm{W}$ chromosome has a dominant female-determining action. However, it contains no coding genes and is practically all composed of transposable elements. The only transcripts from the sexdetermining region of the $\mathrm{W}$ chromosome are noncoding piRNAs transcribed from a sequence Fem, which is present in tandem arrays [Kawaoka et al., 2011; Kiuchi et al., 2014]. Fem is expressed in embryos and silences a masculinizing gene on the $\mathrm{Z}$ chromosome, which in turn regulates splicing of the gene Doublesex $(d s x)$ which determines sex in many insects [Arbeitman et al., 2016]. The Dsx transcript is spliced in a sexual dimorphic manner that leads to 2 proteins with female and male functions and coordinates female versus male development in not just the gonads but all the body. The $d s x$ vertebrate homologue Dmrt1 is a highly conserved transcription factor with an important role in morphogenesis of the testis [Gamble and Zarkower, 2012; Matson and Zarkower, 2012]. While differential splicing of Dmrt1 has been shown in vertebrates [Huang et al., 2017], no evidence currently exists to indicate that vertebrate Dmrt1 genes are regulated by piRNAs. However, ncRNAs may be involved in other vertebrate systems, and there is a growing list of ncRNAs that are transcribed differentially during sex determination in various species [Zhang et al., 2018; Yan et al., 2021].

Although it is established that the linear SRY gene is responsible for sex determination, there is also a testisspecific circular SRY ( $\operatorname{circSRY}$ ) that may play a role in regulation of sex determination in mammals [Capel et al., 1993]. This circSRY has been found in higher abundance than linear SRY in human testis. There are $16 \mathrm{miR}-138$ binding sites on this $\operatorname{circSRY}$, and it has previously been shown to interact with $m i R-138$ in human embryonic kidney cells (HEK293), and therefore could function as a miR-138 sponge [Hansen et al., 2013]. 


\section{Sex Chromosome IncRNA and Dosage Compensation}

Tightly coupled with sex determination are mechanisms to correct for dosage differences in sex chromosomes. Species with highly differentiated sex chromosomes must contend with differential dosage of genes on the X (in XX female/XY male systems) or Z (in ZZ male/ ZW female systems). In Drosophila, genes on the single X in XY males are hypertranscribed by binding with the male-specific lethal-dosage compensation complex (MSL-DCC) that acetylates histones. MSL-DCC contains 5 proteins and 2 lncRNAs, roX1 and roX2 (RNA on X), which function in binding to targets [Meller and Rattner, 2002] and provide binding specificity [Li et al., 2008].

In mammals, XX females have 2 copies of each of the 1,000 or so genes on the $\mathrm{X}$, whereas $\mathrm{XY}$ males have only 1. The solution to gene dosage differences in mammals is to inactivate 1 of the $\mathrm{X}$ chromosomes. Again, $\operatorname{lncRNAs}$ also seem to regulate this process. In eutherian (placental) mammals, this is accomplished through a lncRNA called Xist (X inactive specific transcript) [Disteche, 2012]. The $19-\mathrm{kb}$ transcript is transcribed only from the Xist locus on the inactive $\mathrm{X}$ chromosome and represses the expression of hundreds of genes [Lu et al., 2017]. In both mouse and human, XIST lncRNA coats the X chromosome to be inactivated, and its interaction with many protein and RNA factors (some of which are involved in Drosophila dosage compensation) assembles a silencing domain. Another lncRNA (Firre) attaches it to the nuclear membrane, where several proteins conspire to block transcription [Khosraviani et al., 2019]. There are several other lncRNAs involved in X chromosome inactivation in humans and mouse [Gendrel and Heard, 2014], including $\mathrm{X}$-borne XACT on the human X [Vallot et al., 2013] and an antisense lncRNA Tsix in mouse [Maclary et al., 2013].

Marsupials too have an X chromosome inactivation system, albeit partial and incomplete and paternally imprinted. Searches for an XIST homologue over a decade were unsuccessful, and it was discovered that the region that flanks this gene in eutherians is disrupted in marsupials and monotremes [Hore et al., 2007]. Remarkably, however, a lncRNA was discovered in marsupials with no homology to XIST but with similar properties. This RSX (RNA on the silent $\mathrm{X}$ ) is expressed from the paternal $\mathrm{X}$ and coats it, recruiting other silencing factors in much the same way as the unrelated XIST in eutherians [Grant et al., 2012]. The presence of these unrelated lncRNAs that do a similar job in related mammal lineages suggests that the genome of a common ancestor may have included several - or many - lncRNAs with the propensity to si- lence large regions of chromatin, and different ones took over the sex chromosome silencing function in eutherians and marsupials [Graves, 2016].

In other systems, such as birds, which possess the $\mathrm{ZZ}$ male:ZW female system, there is no such chromosomewide inactivation of one sex chromosome [Disteche, 2012; Livernois et al., 2012]. However, lncRNAs may be involved in dosage compensation in chickens. The gene Dmrt1 has been found to play an important role in avian sex determination through directing testis development in ZZ embryos [Ioannidis et al., 2021]. Dmrt1 overexpression induces the male-specific genes Hemgn, Sox9, and Amh [Lambeth et al., 2014]. However, Dmrt1 knockdown results in feminization of the gonads, leadings to an increase of female marker genes Foxl2 and Aromatase [Smith et al., 2009].

Located on the $\mathrm{Z}$ chromosome of chicken (but not other bird lineages) is the male hypermethylation region $(\mathrm{Mhm})$, a $2.2-\mathrm{kb}$ sequence that is hypermethylated in males and transcribed only in female embryos [Yang et al., 2016]. Mhm produces a 9-kb lncRNA that accumulates in the nucleus adjacent to the Dmrt1 locus [Teranishi et al., 2001]. A second differentially methylated region has been discovered on the chicken $\mathrm{Z}$ chromosome [Sun et al., 2019]. Although it has no sequence homology with Mhm1, it shares several characteristics: highly repetitive structure, higher chromatin accessibility, and enrichment with active histone marks in females. The transcription of lncRNA in a female-biased way, and reduced male:female expression ratios of nearby genes confer a degree of dosage compensation [Bisoni et al., 2005], ultimately affecting development of gonads and other tissues [Roeszler et al., 2012]. It has been suggested that $\mathrm{Mhm}$ is involved in gonadal sex differentiation in chickens, contribution to the reduced expression of Dmrt1 in females [Huang et al., 2005]. This process is thought to occur by $\mathrm{Mhm}$ lncRNA altering the chromatin conformation thereby disrupting transcription of Dmrt1. This is supported by ZZ chicken embryos possessing altered Dmrt1 expression [Roeszler et al., 2012], while adult chicken testis that contain an insertion of $\mathrm{Mhm}$ plasmids dampen the expression of Dmrt1. Collectively, evidence of these ncRNAs in sexual determination demonstrate the pivotal regulatory roles across species.

\section{Y-Borne ncRNAs and Male Traits and Diseases}

ncRNAs have been identified across all human chromosomes, including the $\mathrm{Y}$ and $\mathrm{X}$ chromosomes [Uszczynska-Ratajczak et al., 2018]. As well as 27 protein-cod- 
ing genes, the male-specific region of the human $\mathrm{Y}$ harbours a number of lncRNAs (including circRNAs) and miRNAs [Skaletsky et al., 2003]. Very few studies have determined whether these linear Y-linked ncRNAs play a role in testis determination or other male traits in humans. The haploid nature of the Y chromosome means that conventional methods of chromosomal analysis such as genome-wide association studies cannot be utilised.

Although it was initially thought that the ncRNAs present on the $\mathrm{Y}$ chromosome are only involved in maleexclusive phenotypes such as spermatogenesis and male gonad development [Skaletsky et al., 2003], there is recent emerging evidence to suggest that they play a role in regulating male disease [Molina et al., 2017; Huang et al., 2019; Lai et al., 2019; Lin et al., 2019; Xiao et al., 2019; Brownmiller et al., 2020; Hao and Chen, 2021]. Figure 1 shows Y-borne noncoding genes not only involved in sex determination but other phenotypes in males.

For instance, Y-linked lncRNAs have been described that play a part in early-stage central nervous system (CNS) development in human males [Johansson et al., 2019]. The noncoding transcripts of Y-linked lnc-KDM5D, TTTY14, and TTTY15 were found to be expressed in early CNS development and played functional roles in newborn chimpanzees [Johansson et al., 2019]. These Ylinked $\ln c R N A s$ all have characteristics that suggest a potential functional role such as tissue specificity, polyadenylation, and conservation across primate evolution [Johansson et al., 2019].

There are also emerging concepts that $\mathrm{Y}$ chromosome borne ncRNAs play important roles in regulating male disease. Associations between the $\mathrm{Y}$ chromosome and cardiovascular disease, lung cancer, and prostate cancer have been demonstrated [Molina et al., 2017; Xiao et al., 2019; Brownmiller et al., 2020].

Molina et al. [2017] demonstrated the first lncRNA on the $\mathrm{Y}$ chromosome that could be involved in a disease process. The study investigated the role of IncRNA Lysine Demethylase 5D-4 (lnc-KDM5D-4) in atherosclerosis and coronary artery disease. The authors discovered an intergenic lncRNA transcribed from the $\mathrm{Y}$ chromosome and demonstrated that knocking $\operatorname{lnc}-K D M 5 D-4$ down changed the expression of several genes putatively involved in lipid metabolism. This demonstrates a function of $\operatorname{lnc}-K D M 5 D-4$ in lipid metabolism and suggested that its disruption could lead to formation of increased lipid droplets in hepatocytes. This increase is a known factor that contributes to the chronic inflammatory process underpinning coronary artery disease.

Noncoding Genes on Sex Chromosomes
The noncoding testis-specific transcript, Y-linked 15 (TTTY15) on the human Y has been implicated in several male diseases [Huang et al., 2019; Lai et al., 2019; Xiao et al., 2019; Hao and Chen, 2021]. Xiao et al. [2019] found that TTTY15 was upregulated in prostate cancer tissues with the ability to promote prostate cancer progression. Forkhead box protein A1 (FOXA1) plays an important role in prostate cancer development and is also a regulator of TTTY15. TTTY15 "sponges" the let-7 family to alter the expression of Fibronectin 1 (FN1), which is a relevant mediator of cancer metastasis [Xiao et al., 2019]. In another study Lai et al. [2019] found that TTTY15 inhibits non-small cell lung cancer (NSCLC) metastasis and proliferation. These authors found that lower expression levels of TTTY15 had an association with tumor-node-metastasis and concluded that low expression correlates with worse prognosis among patients with NSCLC [Lai et al., 2019].

Additionally, a group of Y-linked long intergenic noncoding RNAs (lincRNAs) have been implicated in male NSCLC radiation sensitivity [Brownmiller et al., 2020]. Expression of 3 Y-linked lncRNAs, linc-SPRY3-2, linc$S P R Y 3-3$, and linc-SPRY3-4, were detected in radiosensitive male NSCLC cell lines following radiation and not in radioresistant male NSCLC cell lines [Brownmiller et al., 2020]. The radioresistant male NSCLC cell lines demonstrated a loss of the $\mathrm{Y}$ chromosome (LOY) [Brownmiller et al., 2020]. Microarray and RNA sequencing analysis illustrated a negative correlation amongst the LOY, linc$S P R Y 3-2 / 3 / 4$ expression, and overall survival. This study therefore suggests that linc-SPRY3-2/3/4 expression and LOY could be a useful biomarker of successful radiation therapy in NSCLC patients [Brownmiller et al., 2020].

There is increasing evidence that circRNAs are involved in development and progression of male disease. To understand the role of circRNAs on the Y chromosome in the context of coronary artery disease, Lin et al. [2019] measured circRNAs in peripheral blood of coronary artery disease patients. They found several significantly upregulated Y-linked circRNAs. These included circRNAs associated with the MSY genes UTY, KDM5D, and USP9Y [Lai et al., 2019]. However, these studies are yet to define the mechanistic role of these circRNAs.

\section{Concluding Remarks}

The last few decades of sex chromosome research have come far in elucidating how the $\mathrm{Y}$ chromosome has evolved and how it contributes to sex determination. This 
is true in terms of the protein-coding genes. The noncoding content of the $\mathrm{Y}$ and the $\mathrm{X}$ are still underexplored. There is an emerging appreciation that Y-linked ncRNAs may play a bigger role developmentally. Few examples through evolution are the Fem piRNA in the silkworm and the lncRNA $S x l$ in Drosophila. In humans, further evidence is also emerging that these ncRNAs contribute to development and health. Y-linked lncRNAs such as lnc-KDM5D, TTTY14, and TTTY15 are increasingly found to be associated with disease. Since these functional ncRNAs play a time-critical role, it is important and more difficult to study the role of these molecules without genome editing. Nonetheless, further studies exploring the function of these Y-linked ncRNAs and how they interact with other chromosomes, including the $\mathrm{X}$, are warranted.

\section{Author Contributions}

Data curation: M.C.M., M-R.A.M., J.A.M.G., F.J.C. Original draft preparation: M.C.M., M-R.A.M., J.A.M.G. Writing - review and editing: M.C.M., M-R.A.M., J.A.M.G., F.J.C. Supervision: M.C.M., J.A.M.G., F.J.C. All authors have read and agreed to the published version of the manuscript.

\section{Funding Sources}

This research was funded by National Health and Medical Research Council of Australia, grant number APP1123472.

\section{Conflict of Interest Statement}

The authors declare no conflict of interest.

\section{References}

Alam SMI, Sarre SD, Gleeson D, Georges A, Ezaz T. Did lizards follow unique pathways in sex chromosome evolution? Genes (Basel). 2018; 9(5):239.

Arbeitman MN, New FN, Fear JM, Howard TS, Dalton JE, Graze RM. Sex differences in Drosophila somatic gene expression: Variation and regulation by doublesex. G3 (Bethesda). 2016;6(7):1799-808.

Arnold AP. A general theory of sexual differentiation. J Neurosci Res. 2017;95(1-2):291-300.

Bachtrog D. Y-chromosome evolution: emerging insights into processes of Y-chromosome degeneration. Nat Rev Genet. 2013;14(2):11324.

Bachtrog D, Mank JE, Peichel CL, Kirkpatrick M, Otto SP, Ashman TL, et al. Sex determination: Why so many ways of doing it? PLoS Biol. 2014;12(7):e1001899.

Bellott DW, Hughes JF, Skaletsky H, Brown LG, Pyntikova T, Cho TJ, et al. Mammalian Y chromosomes retain widely expressed dosage-sensitive regulators. Nature. 2014; 508(7497):494-9.

Bisoni L, Batlle-Morera L, Bird AP, Suzuki M, McQueen HA. Female-specific hyperacetylation of histone $\mathrm{H} 4$ in the chicken $\mathrm{Z}$ chromosome. Chromosome Res. 2005;13(2):205-14.

Brownmiller T, Juric JA, Ivey AD, Harvey BM, Westemeier ES, Winters MT, et al. Y chromosome lncRNA are involved in radiation response of male non-small cell lung cancer cells. Cancer Res. 2020;80(19):4046-57.

Capel B, Swain A, Nicolis S, Hacker A, Walter M, Koopman P, et al. Circular transcripts of the testis-determining gene Sry in adult mouse testis. Cell. 1993;73(5):1019-30.

Carninci P, Kasukawa T, Katayama S, Gough J, Frith M C, Maeda N, et al., FANTOM Consortium; RIKEN Genome Exploration Research Group and Genome Science Group
(Genome Network Project Core Group). The transcriptional landscape of the mammalian genome. Science. 2005;309(5740):1559-63.

Charlesworth B. The evolution of chromosomal sex determination and dosage compensation. Curr Biol. 1996;6(2):149-62.

Cline TW. Autoregulatory functioning of a Drosophila gene product that establishes and maintains the sexually determined state. Genetics. 1984;107(2):231-77.

Cortez D, Marin R, Toledo-Flores D, Froidevaux L, Liechti A, Waters PD, et al. Origins and functional evolution of $\mathrm{Y}$ chromosomes across mammals. Nature. 2014;508(7497): 488-93.

Disteche CM. Dosage compensation of the sex chromosomes. Annu Rev Genet. 2012;46(1): 537-60.

Ellegren H. Sex-chromosome evolution: recent progress and the influence of male and female heterogamety. Nat Rev Genet. 2011;12(3): $157-66$.

Farazi TA, Juranek SA, Tuschl T. The growing catalog of small RNAs and their association with distinct Argonaute/Piwi family members. Development. 2008;135(7):1201-14.

Fatica A, Bozzoni I. Long non-coding RNAs: new players in cell differentiation and development. Nat Rev Genet. 2014;15(1):7-21.

Gamble T, Zarkower D. Sex determination. Curr Biol. 2012;22(8):R257-62.

Gendrel AV, Heard E. Noncoding RNAs and epigenetic mechanisms during X-chromosome inactivation. Annu Rev Cell Dev Biol. 2014; 30:561-80.

Ghenu AH, Bolker BM, Melnick DJ, Evans BJ. Multicopy gene family evolution on primate Y chromosomes. BMC Genomics. 2016; 17(1):157.

Girard A, Sachidanandam R, Hannon GJ, Carmell MA. A germline-specific class of small
RNAs binds mammalian Piwi proteins. Nature. 2006;442(7099): 199-202.

Golden DE, Gerbasi VR, Sontheimer EJ. An inside job for siRNAs. Mol Cell. 2008;31(3): 309-12.

Grant J, Mahadevaiah SK, Khil P, Sangrithi MN, Royo H, Duckworth J, et al. Rsx is a metatherian RNA with Xist-like properties in X-chromosome inactivation. Nature. 2012; 487(7406):254-8.

Graves JA. Background and overview of comparative genomics. ILAR J. 1998;39(2-3):48-65.

Graves JA. Sex chromosome specialization and degeneration in mammals. Cell. 2006;124(5): 901-14.

Graves JA. How to evolve new vertebrate sex determining genes. Dev Dyn. 2013;242(4):354-9.

Graves JA. Evolution of vertebrate sex chromosomes and dosage compensation. Nat Rev Genet. 2016;17(1):33-46.

Graves JA, Peichel CL. Are homologies in vertebrate sex determination due to shared ancestry or to limited options? Genome Biol. 2010; 11(4):205.

Guttman M, Donaghey J, Carey BW, Garber M, Grenier JK, Munson G, et al. lincRNAs act in the circuitry controlling pluripotency and differentiation. Nature. 2011;477(7364):295-300.

Hansen TB, Jensen TI, Clausen BH, Bramsen JB, Finsen B, Damgaard CK, et al. Natural RNA circles function as efficient microRNA sponges. Nature. 2013;495(7441):384-8.

Hao C, Chen S. Knockdown of lncRNA TTTY15 alleviates ischemia/reperfusion-induced inflammation and apoptosis of PC12 cells by targeting miR-766-5p. Exp Ther Med. 2021; 21(5):511.

Holdt LM, Kohlmaier A, Teupser D. Molecular roles and function of circular RNAs in eukaryotic cells. Cell Mol Life Sci. 2018;75(6): 1071-98. 
Holleley CE, O'Meally D, Sarre SD, Marshall Graves JA, Ezaz T, Matsubara K, et al. Sex reversal triggers the rapid transition from genetic to temperature-dependent sex. Nature. 2015;523(7558):79-82.

Hore TA, Koina E, Wakefield MJ, Marshall Graves JA. The region homologous to the X-chromosome inactivation centre has been disrupted in marsupial and monotreme mammals. Chromosome Res. 2007;15(2):147-61.

Huang S, Ye L, Chen H. Sex determination and maintenance: the role of DMRT1 and FOXL2. Asian J Androl. 2017;19(6):619-24.

Huang S, Tao W, Guo Z, Cao J, Huang X. Suppression of long noncoding RNA TTTY15 attenuates hypoxia-induced cardiomyocytes injury by targeting miR-455-5p. Gene. 2019; 701:1-8.

Huang X, Guo Y, Shui Y, Gao S, Yu H, Cheng H, et al. Multiple alternative splicing and differential expression of dmrtl during gonad transformation of the rice field eel. Biol Reprod. 2005;73(5):1017-24.

Hughes JF, Skaletsky H, Brown LG, Pyntikova T, Graves T, Fulton RS, et al. Strict evolutionary conservation followed rapid gene loss on human and rhesus $\mathrm{Y}$ chromosomes. Nature. 2012;483(7387):82-6.

Ioannidis J, Taylor G, Zhao D, Liu L, Idoko-Akoh A, Gong D, et al. Primary sex determination in birds depends on DMRT1 dosage, but gonadal sex does not determine adult secondary sex characteristics. Proc Natl Acad Sci U S A. 2021;118(10).

Janzen FJ, Paukstis GL. Environmental sex determination in reptiles: ecology, evolution, and experimental design. Q Rev Biol. 1991;66(2): 149-79.

Jeck WR, Sorrentino JA, Wang K, Slevin MK, Burd CE, Liu J, et al. Circular RNAs are abundant, conserved, and associated with ALU repeats. RNA. 2013;19(2):141-57.

Jeng SR, Wu GC, Yueh WS, Kuo SF, Dufour S, Chang CF. Dmrtl (doublesex and mab-3-related transcription factor 1) expression during gonadal development and spermatogenesis in the Japanese eel. Gen Comp Endocrinol. 2019;279:154-63.

Johansson MM, Pottmeier P, Suciu P, Ahmad T, Zaghlool A, Halvardson J, et al. Novel Y-chromosome long non-coding RNAs expressed in human male CNS during early development. Front Genet. 2019;10:891.

Kawaoka S, Kadota K, Arai Y, Suzuki Y, Fujii T, Abe $\mathrm{H}$, et al. The silkworm $\mathrm{W}$ chromosome is a source of female-enriched piRNAs. RNA. 2011;17(12):2144-51.

Khosraviani N, Ostrowski LA, Mekhail K. Roles for non-coding RNAs in spatial genome organization. Front Cell Dev Biol. 2019;7(336):336.

Kim VN, Han J, Siomi MC. Biogenesis of small RNAs in animals. Nat Rev Mol Cell Biol. 2009; 10(2):126-39.

Kiuchi T, Koga H, Kawamoto M, Shoji K, Sakai $\mathrm{H}$, Arai $\mathrm{Y}$, et al. A single female-specific piR$\mathrm{NA}$ is the primary determiner of sex in the silkworm. Nature. 2014;509(7502):633-6.
Klattenhoff C, Theurkauf W. Biogenesis and germline functions of piRNAs. Development. 2008;135(1):3-9.

Lai IL, Chang YS, Chan WL, Lee YT, Yen JC, Yang $\mathrm{CA}$, et al. Male-specific long noncoding RNA TTTY15 inhibits non-small cell lung cancer proliferation and metastasis via TBX4. Int J Mol Sci. 2019;20(14):3473.

Lambeth LS, Raymond CS, Roeszler KN, Kuroiwa A, Nakata T, Zarkower D, et al. Over-expression of DMRT1 induces the male pathway in embryonic chicken gonads. Dev Biol. 2014; 389(2):160-72.

Lau NC, Seto AG, Kim J, Kuramochi-Miyagawa S, Nakano T, Bartel DP, et al. Characterization of the piRNA complex from rat testes. Science. 2006;313(5785):363-7.

Legnini I, Di Timoteo G, Rossi F, Morlando M, Briganti F, Sthandier O, et al. Circ-ZNF609 is a circular RNA that can be translated and functions in myogenesis. Mol Cell. 2017; 66(1):22-e9.

Li F, Schiemann AH, Scott MJ. Incorporation of the noncoding roX RNAs alters the chromatin-binding specificity of the Drosophila MSL1/MSL2 complex. Mol Cell Biol. 2008; 28(4):1252-64.

Lin F, Zhao G, Chen Z, Wang X, Lv F, Zhang Y, et al. circRNA-miRNA association for coronary heart disease. Mol Med Rep. 2019;19(4): 2527-36.

Livernois AM, Graves JA, Waters PD. The origin and evolution of vertebrate sex chromosomes and dosage compensation. Heredity (Edinb). 2012;108(1):50-8.

Lu Z, Carter AC, Chang HY. Mechanistic insights in X-chromosome inactivation. Philos Trans R Soc Lond B Biol Sci. 2017;372(1733).

Maclary E, Hinten M, Harris C, Kalantry S. Long nonoding RNAs in the $\mathrm{X}$-inactivation center. Chromosome Res. 2013;21(6-7):601-14.

Matson CK, Zarkower D. Sex and the singular DM domain: insights into sexual regulation, evolution and plasticity. Nat Rev Genet. 2012; 13(3):163-74.

Meller VH, Rattner BP. The roX genes encode redundant male-specific lethal transcripts required for targeting of the MSL complex. EMBO J. 2002;21(5):1084-91.

Memczak S, Papavasileiou P, Peters O, Rajewsky $\mathrm{N}$. Identification and characterization of circular RNAs as a new class of putative biomarkers in human blood. PLoS One. 2015; 10(10):e0141214.

Mercer TR, Dinger ME, Mattick JS. Long noncoding RNAs: insights into functions. Nat Rev Genet. 2009;10(3):155-9.

Molina E, Chew GS, Myers SA, Clarence EM, Eales JM, Tomaszewski M, et al. A novel Yspecific long non-coding RNA associated with cellular lipid accumulation in HepG2 cells and atherosclerosis-related genes. Sci Rep. 2017;7(1):16710.

Morgan AP, Pardo-Manuel De Villena F. Sequence and structural diversity of mouse $\mathrm{Y}$ chromosomes. Mol Biol Evol. 2017;34(12): 3186-204.
Mulugeta E, Wassenaar E, Sleddens-Linkels E, Van Ijcken WF, Heard E, Grootegoed JA, et al. Genomes of Ellobius species provide insight into the evolutionary dynamics of mammalian sex chromosomes. Genome Res. 2016; 26(9):1202-10.

Mulvey BB, Olcese U, Cabrera JR, Horabin JI. An interactive network of long non-coding RNAs facilitates the Drosophila sex determination decision. Biochim Biophys Acta. 2014; 1839(9):773-84.

Okazaki Y, Furuno M, Kasukawa T, Adachi J, Bono H, Kondo S, et al., FANTOM Consortium; RIKEN Genome Exploration Research Group Phase I \& II Team. Analysis of the mouse transcriptome based on functional annotation of 60,770 full-length cDNAs. Nature. 2002;420(6915):563-73.

Ortega MT, Bivens NJ, Jogahara T, Kuroiwa A, Givan SA, Rosenfeld CS. Sexual dimorphism in brain transcriptomes of Amami spiny rats (Tokudaia osimensis): a rodent species where males lack the Y chromosome. BMC Genomics. 2019;20(1):87.

Pamudurti NR, Bartok O, Jens M, Ashwal-Fluss R, Stottmeister C, Ruhe L, et al. Translation of CircRNAs. Mol Cell. 2017;66(1):9-e7.

Prothero KE, Stahl JM, Carrel L. Dosage compensation and gene expression on the mammalian X chromosome: one plus one does not always equal two. Chromosome Res. 2009; 17(5):637-48.

Qu S, Yang X, Li X, Wang J, Gao Y, Shang R, et al. Circular RNA: A new star of noncoding RNAs. Cancer Lett. 2015;365(2):141-8.

Quintana-Murci L, Fellous M. The human Y chromosome: The biological role of a "functional wasteland". J Biomed Biotechnol. 2001; $1: 18$.

Roeszler KN, Itman C, Sinclair AH, Smith CA. The long non-coding RNA, MHM, plays a role in chicken embryonic development, including gonadogenesis. Dev Biol. 2012; 366(2):317-26.

Saunders PA, Neuenschwander S, Perrin N. Impact of deleterious mutations, sexually antagonistic selection, and mode of recombination suppression on transitions between male and female heterogamety. Heredity (Edinb). 2019; 123(3):419-28

Skaletsky H, Kuroda-Kawaguchi T, Minx PJ, Cordum HS, Hillier L, Brown LG, et al. The malespecific region of the human $\mathrm{Y}$ chromosome is a mosaic of discrete sequence classes. Nature. 2003;423(6942):825-37.

Smith CA, Roeszler KN, Ohnesorg T, Cummins DM, Farlie PG, Doran TJ, et al. The avian Zlinked gene DMRT1 is required for male sex determination in the chicken. Nature. 2009; 461(7261):267-71.

Song R, Hennig GW, Wu Q, Jose C, Zheng H, Yan W. Male germ cells express abundant endogenous siRNAs. Proc Natl Acad Sci U S A. 2011;108(32):13159-64. 
Sun D, Maney DL, Layman TS, Chatterjee P, Yi SV. Regional epigenetic differentiation of the $\mathrm{Z}$ chromosome between sexes in a female heterogametic system. Genome Res. 2019; 29(10):1673-84.

Teranishi M, Shimada Y, Hori T, Nakabayashi O, Kikuchi T, Macleod T, et al. Transcripts of the $\mathrm{MHM}$ region on the chicken $\mathrm{Z}$ chromosome accumulate as non-coding RNA in the nucleus of female cells adjacent to the DMRT1 locus. Chromosome Res. 2001;9(2):147-65.

Trukhina AV, Lukina NA, Wackerow-Kouzova ND, Smirnov AF. The variety of vertebrate mechanisms of sex determination. Biomed Res Int. 2013;2013:587460-8.

Tsend-Ayush E, O'Sullivan LA, Grützner FS, Onnebo SM, Lewis RS, Delbridge ML, et al. RBMX gene is essential for brain development in zebrafish. Dev Dyn. 2005;234(3): 682-8.

Ulitsky ID. lincRNAs: genomics, evolution, and mechanisms. Cell. 2013;154(1):26-46.

Uszczynska-Ratajczak B, Lagarde J, Frankish A, Guigó R, Johnson R. Towards a complete map of the human long non-coding RNA transcriptome. Nat Rev Genet. 2018;19(9):53548.
Vagin VV, Sigova A, Li C, Seitz H, Gvozdev V, Zamore PD. A distinct small RNA pathway silences selfish genetic elements in the germline. Science. 2006;313(5785):320-4

Vallot C, Huret C, Lesecque Y, Resch A, Oudrhiri N, Bennaceur-Griscelli A, et al. XACT, a long noncoding transcript coating the active $\mathrm{X}$ chromosome in human pluripotent cells. Nat Genet. 2013;45(3):239-41.

Veyrunes F, Waters PD, Miethke P, Rens W, McMillan D, Alsop AE, et al. Bird-like sex chromosomes of platypus imply recent origin of mammal sex chromosomes. Genome Res. 2008;18(6):965-73.

Watanabe T, Takeda A, Tsukiyama T, Mise K, Okuno T, Sasaki H, et al. Identification and characterization of two novel classes of small RNAs in the mouse germline: retrotransposon-derived siRNAs in oocytes and germline small RNAs in testes. Genes Dev. 2006;20(13): 1732-43.

Wu Z, Liu X, Liu L, Deng H, Zhang J, Xu Q, et al. Regulation of lncRNA expression. Cell Mol Biol Lett. 2014;19(4):561-75.
Xiao G, Yao J, Kong D, Ye C, Chen R, Li L, et al. The long noncoding RNA TTTY15, which is located on the $\mathrm{Y}$ chromosome, promotes prostate cancer progression by sponging let7. Eur Urol. 2019;76(3):315-26.

Yan H, Liu Q, Jiang J, Shen X, Zhang L, Yuan Z, et al. Identification of sex differentiation-related microRNA and long non-coding RNA in Takifugu rubripes gonads. Sci Rep. 2021; 11(1):7459.

Yang X, Deng J, Zheng J, Xia L, Yang Z, Qu L, et al. A window of MHM demethylation correlates with key events in gonadal differentiation in the chicken. Sex Dev. 2016;10(3):152-8.

Yoshimoto S, Ito M. A ZZ/ZW-type sex determination in Xenopus laevis. FEBS J. 2011;278(7): $1020-6$.

Yoshimoto S, Ikeda N, Izutsu Y, Shiba T, Takamatsu N, Ito M. Opposite roles of DMRT1 and its $\mathrm{W}$-linked paralogue, DM-W, in sexual dimorphism of Xenopus laevis: implications of a ZZ/ZW-type sex-determining system. Development. 2010;137(15):2519-26.

Zhang J, Yu P, Zhou Q, Li X, Ding S, Su S, et al. Screening and characterisation of sex differentiation-related long non-coding RNAs in Chinese soft-shell turtle (Pelodiscus sinensis). Sci Rep. 2018;8(1):8630. 